\title{
O FLUXo TEXTUAL EM JORGE LUIS BORGES
}

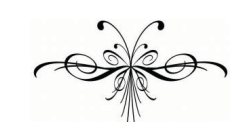

\section{RICHARD COSTA}

$\mathrm{J}$

orge Luis Borges é mundialmente celebrado como poeta, ficcionista e ensaísta. Sua atividade como tradutor não é prestigiada com a mesma fama, mas compõe um corpo substancial de obras. Uma bibliografia ${ }^{1}$ indica que traduziu obras de Edgar Allan Poe, Franz Kafka, Hermann Hesse, Rudyard Kipling, Herman Melville, André Gide, William Faulkner, Walt Whitman, Virginia Woolf, Thomas Browne e G.K. Chesterton.

É seguro dizer que não foi somente como mero leitor-espectador que o escritor argentino percorreu várias traduções dos poemas épicos de Homero, mas sim como um tradutor experiente, dotado de senso crítico e consciência diante dos problemas subtextuais da tradução. O resultado dessa dedicada erudição foi compactado num ensaio breve e denso: As versões homéricas.

Abordamos uma questão essencial apontada nesse ensaio, que denominamos "fluxo textual." Utilizamos trechos de outras obras e outros autores para ilustrar concepções paralelas. com o propósito de demonstrar a qualidade instável da substância "texto."

Na primeira linha do ensaio As Versões Homéricas, Borges sugere que o problema proposto pela arte da tradução é "consubstancial com as letras." 2 Pode-se entrever nessa sugestão a ideia de que a tradução está mais do que intimamente vinculada ao ofício literário, posto que o próprio ato de escrever é, de certa maneira, traduzir processos mentais abstratos e dar-lhes uma existência concreta na forma de palavras escritas. No mesmo parágrafo, o autor postula que a tradução "parece destinada a ilustrar a discussão estética."3 A distinção entre a tradução literária e a produção literária se configura de forma que, na tradução, "o modelo proposto à sua imitação é um texto visível, não um labirinto inestimável de projetos pretéritos ou a acatada tentação momentânea de uma facilidade." Esse "labirinto de

\footnotetext{
${ }^{1} \mathrm{http}: / /$ www.cervantes.es/imagenes/File/biblioteca/bibliografias/borges_jorge_luis\%281\%29.pdf

2 Jorge Luis Borges, Discussão, 1932, in Obras Completas Vol. I, p. 255.

${ }^{3}$ Ibid.

${ }^{4}$ Ibid.
} 
projetos pretéritos," por sua vez, seria uma definição peculiar dos problemas enfrentados por todo autor que se propõe escrever uma obra. Ao dar início a um projeto, um autor hipotético nunca possui em sua memória um modelo perfeitamente exato de todas as páginas, linhas e palavras que escreverá. Ele não é meramente um copista que transcreve as palavras ditadas por sua memória. Todo autor enfrenta momentos de dúvida e incerteza diante do rumo escolhido por suas palavras, muitas vezes sendo incapaz sequer de prosseguir na composição da obra. No mundo anglófono, criou-se inclusive uma expressão que reflete tal angústia de escritores: writer's block. Esse bloqueio, essa hesitação diante da página em branco, é uma importante distinção entre o ato de escrever e o ato de traduzir.

Embora a matéria-prima do tradutor seja mais concreta e definida, não é menos problemática a aplicação de sua técnica. Um texto, nota Borges, tem "repercussões incalculáveis." No processo de tradução, o tradutor geralmente se esforça por "manter intacta e central uma reserva incalculável de sombra." Essa "reserva de sombra" pode ser interpretada como um núcleo de significado que se aproxima da essência do texto. Assim como toda sombra procede de um objeto diante da luz, poderíamos formular uma metáfora: todo significado procede de um objeto abstrato diante da luz da consciência. Para preservar a sombra do significado é necessário preservar a luz da consciência. A partir dessa afirmação, passamos do domínio literário ao domínio psicológico ou fenomenológico. O que é, pois, a consciência? Não empreenderemos uma genealogia das inúmeras definições e discussões em torno dessa questão. Mas tomemos a liberdade de descrever o que a consciência representa em nossas vidas mentais.

Um fluxo incessante de desejos, veleidades, observações, palavras, fragmentos, memórias, imagens, distrações, impressões dos sentidos... A consciência como fluxo foi utilizada como técnica literária por vários escritores modernistas $^{7}$, mas a expressão stream of consciousness foi cunhada antes pelo psicólogo William James ${ }^{8}$. Assim, a consciência emite sua luz metafórica, incidindo sobre objetos abstratos e formando sombras onde o significado reside.

Talvez essa metáfora seja elaborada demais; portanto, retornemos ao texto de Borges. $\mathrm{O}$ autor argentino se refere às várias versões da Ilíada como "diversas perspectivas de um fato móvel, [...] um longo lance experimental de omissões e ênfases." A noção de "diversas perspectivas" é essencial para compreender a complexidade multifacetada da concepção de texto na visão de Borges. Além disso, poderíamos evocar também a importância da sombra e da perspectiva nas artes visuais. A partir desse perspectivismo estético, Borges declara com inquestionável autoridade: "Pressupor que toda recombinação de elementos é obrigatoriamente inferior a seu original, é pressupor que o rascunho 9 é obrigatoriamente inferior ao

\footnotetext{
${ }^{5}$ Ibid.

${ }^{6}$ Ibid.

${ }^{7}$ A obra Les Lauriers sont coupés (1887) de Édouard Djardin é tida como pioneira da técnica literária do fluxo de consciência. No mundo anglófono James Joyce, Virginia Woolf e Samuel Beckett destacam-se como pioneiros e inovadores da técnica. Na Literatura Brasileira, usa-a em toda sua obra Clarice Lispector.

${ }^{8}$ Ela aparece em múltiplas ocorrências em sua obra Principles of Psychology (1890).

${ }^{9}$ Ibid.
} 
rascunho $\mathrm{H}$ - já que não pode haver senão rascunhos. $\mathrm{O}$ conceito de texto definitivo não corresponde senão à religião ou ao cansaço."10

Com tal asserção, comprovamos a contumácia do autor diante do que denomina "a superstição da inferioridade das traduções — amoedada no consabido adágio italiano." 11 É interessante notar que Borges utiliza a palavra superstição para se referir a essa tendência, a mesma palavra que utilizou em outro ensaio do mesmo volume: A supersticiosa ética do leitor. Nesse ensaio, Borges discute outro assunto intimamente conectado ao ponto em questão: a "superstição do estilo." Para o autor, "os que sofrem dessa superstição entendem por estilo não a eficácia ou ineficácia de uma página, mas as habilidades aparentes do escritor: suas comparações, sua acústica, os episódios de sua pontuação e de sua sintaxe." ${ }^{12}$ Entre essas habilidades aparentes, Borges inclui também a adjetivação como atributo decorativo de uma frase, e a falsa concisão. "Generalizou-se tanto essa inibição," conclui, "que quase não restam mais leitores, no sentido ingênuo da palavra, mas todos são críticos potenciais." 13

Para provar que a superstição não é inerente a leitores leigos, o autor cita passagens de escritores argentinos comentando o estilo de Dom Quixote, e verifica nas opiniões eruditas o mesmo hábito tendencioso: julgar um estilo pela superfície do texto, em vez de considerar sua substância mais importante do que sua forma. Notemos, também, que a obstinação de Borges não é uma questão pessoal, pois o próprio estilo do autor é distinto e heteróclito o suficiente para não ser caracterizado como um escritor culpado de uma suposta negligência estilística.

Tomemos a liberdade de citar integralmente um parágrafo desse mesmo ensaio para ilustrar um ponto que será essencial para a compreensão de nossa tese central.

Essa fatuidade do estilo se enfatua em outra fatuidade mais patética, a da perfeição. Não há um escritor métrico, por mais casual e nulo que seja, que não tenha cinzelado (o verbo costuma figurar em sua conversa) seu soneto perfeito, monumento minúsculo que custodia sua possível imortalidade, e que as novidades e aniquilações do tempo deverão respeitar. Trata-se de um soneto sem rípios, geralmente, mas que é todo ele um rípio: ou seja, um resíduo, uma inutilidade. Essa falácia em perduração (sir Thomas Browne: Urn Burial) foi formulada e recomendada por Flaubert nessa sentença: 'A correção (no sentido mais elevado da palavra) faz com o pensamento o que fizeram as águas do Estige com o corpo de Aquiles: tornam-no invulnerável e indestrutível' (Correspondance, II, p. 199). A sentença é categórica, mas não conheço nenhuma experiência que a confirme. (Dispenso as virtudes tônicas do Estige; essa reminiscência infernal não é um argumento, é uma ênfase.) A página de perfeição, a página na qual nenhuma palavra pode ser alterada sem prejuízo, é a mais precária de todas. As mudanças de linguagem apagam os sentidos laterais e os matizes; a página "perfeita" é a que é composta desses valores sutis, e a que com maior facilidade se desgasta. Inversamente, a página que tem vocação de imortalidade pode atravessar o fogo das erratas, das versões aproximativas, das leituras distraídas, das incompreensões,

\footnotetext{
${ }^{10}$ Ibid.

${ }^{11}$ Ibid.

${ }^{12}$ Jorge Luis Borges, Discussão, 1932, in Obras Completas Vol. I, p. 214.

${ }^{13}$ Ibid.
} 
sem deixar a alma na prova. Não se pode mudar impunemente (é o que afirmam aqueles que trabalham no estabelecimento de seu texto) nenhuma das linhas fabricadas por Góngora; mas o Quixote ganha batalhas póstumas contra seus tradutores e sobrevive a toda versão descuidada. Heine, que nunca o ouviu em espanhol, pôde celebrá-lo para sempre. Mais vivo é o fantasma alemão ou escandinavo ou hindustânico do Quixote que os ansiosos artifícios verbais do estilista. ${ }^{14}$

Admiremos a força argumentativa e ilustrativa desse trecho antes de proceder com nosso comentário. O desprezo do autor pelo ideal da perfeição é quase absoluto; porém, não podemos deixar de notar certos indícios de que praticou a arte da correção em várias de suas obras. No prólogo da edição de 1969 de seu primeiro livro de poemas, Fervor de Buenos Aires, o autor confessa que, embora não tenha reescrito o livro, "mitigou seus excessos barrocos, limou asperezas, eliminou sentimentalismos e expressões vagas." Outros exemplos poderiam ser apresentados, como as notas de rodapé póstumas inseridas em obras de ensaios, anos depois de sua publicação original.

A evidência principal dos hábitos revisionistas de Borges é a epígrafe da obra Discussão - "Eis o problema de não publicar as obras: passar a vida reescrevendo." ${ }^{15}$ Para Borges, o ato de escrever implica o ato de reescrever, e a publicação é um método para abandonar as intermináveis sessões cíclicas de revisão e correção. Como Paul Valéry, Borges acreditava que uma obra não pode ser terminada, mas somente abandonada ${ }^{16}$.

Voltemos às Versões Homéricas para observar essa questão do ponto de vista do leitor: "Não há um bom texto que não pareça invariável e definitivo se o praticamos um número suficiente de vezes." ${ }^{17}$ Essa recorrência das leituras, essa eterna releitura dos clássicos a que Borges alude também figura no processo criativo. Efraín Kristal, um dos tradutores de Borges para o inglês, comentou em uma discussão em formato podcast, In Our Time da Rádio $\mathrm{BBC}^{18}$ :

O fato da tradução ser central no processo criativo de Borges, e na tessitura mesma de suas histórias, em que a maior parte de seus protagonistas são, eles mesmos, tradutores, deriva do sentido profundo que Borges tem da literatura. Borges vianos apenas como reutilizadores e recicladores de ideias, histórias e metáforas, havendo dito certa vez que 3000 anos após a Ilíada e a Odisséia não era provável que algum novo tema ou metáfora literária surgissem que já não houvessem sido tentados. Desse modo, estamos, aos olhos de Borges, condenados a traduzir, a editar, a alterar ênfases, a combinar.

\footnotetext{
${ }^{14}$ Ibid., p. 215-216.

${ }^{15}$ Jorge Luis Borges, Discussão, 1932, in Obras Completas Vol. I, p. 183. (Fonte apresentada pelo autor: Alfonso Reyes: Cuestiones Gongorinas, 60.)

${ }^{16}$ Paul Valéry, Au sujet du Cimetière martin, in Oeuvres I, Bibliothèque de la Pléiade, 1957, p.1497: "[...] un ouvrage n'est jamais achevé (...) mais abandonné [...]".

${ }^{17}$ Jorge Luis Borges, Discussão, 1932, in Obras Completas Vol. I, p. 255.

${ }^{18} \mathrm{http} / / /$ www.bbc.co.uk/radio4/history/inourtime/research.shtml
} 
É com a consciência desse dilema que Borges se revolta diante das superstições literárias, diante da idolatria do texto original, definitivo, abstrato, imutável, intocável como uma língua morta. Por esse motivo, o autor celebra as diversas versões homéricas, as quais compõem "uma livraria internacional de obras em prosa e verso, dos dísticos de Chapman a Authorized Version de Andrew Lang ou o drama clássico francês de Bérard ou a saga vigorosa de Morris ou o irônico romance burguês de Samuel Butler." ${ }^{19} \mathrm{O}$ autor atribui essa polivalência das versões à dificuldade categórica de saber o que pertence ao poeta Homero e o que pertence à linguagem; dificuldade que resulta na "possibilidade de tantas versões, todas sinceras, genuínas e divergentes." ${ }^{20}$ A exaltação da polissemia e da diversidade é uma das respostas que Borges dá à questão essencial: o que pertence ao autor, e o que pertence à linguagem?

Borges prossegue num comentário detalhado de literatura comparada. Ao justapor um trecho da Odisséia em suas várias versões inglesas, o autor aponta para a conclusão do ensaio: qual das muitas traduções é a mais fiel? "Nenhuma, ou todas. Se a fidelidade deve ser prestada às imaginações de Homero, aos irrecuperáveis homens e dias que ele imaginou, nenhuma pode sê-lo para nós; todas para um grego do século dez." ${ }^{, 21}$ Mas, talvez para apaziguar o leitor, Borges elege a tradução de Samuel Butler como a mais fiel, o que não implica que seja a melhor.

Para compreender a ambivalência do conceito de fidelidade na visão de Borges, citamos uma frase do ensaio Sobre el Vathek de William Beckford, encontrado na obra Otras Inquisiciones: El original es infiel a la traducción. ${ }^{22}$ Vathek, um romance gótico de 1782 foi escrito originalmente em francês por William Beckford. Nesse ensaio, Borges o compara a tradução de 1786 de Samuel Henley, e por fim apresenta esse veredicto paradoxal e provocativo: o original é infiel à tradução. $\mathrm{O}$ autor inglês, William Beckford, escreveu o romance em francês, diz-se, em cerca de três dias, influenciado por uma tradução francesa das Mil e Uma Noites e pelos romances orientalistas de Voltaire. A tradução de Samuel Henley para o inglês foi certamente composta num estado de espírito mais sóbrio e premeditado - Henley era um sacerdote anglicano e erudito -, e podemos imaginar Borges lendo ambas as versões "originais", notando, assim, a volatilidade do conceito de fidelidade, e a impossibilidade de um texto "original."

É evidente que existem textos originários, dos quais traduções são realizadas, e que constituem o ponto de partida do processo criativo. Porém, quando Borges evoca "o fantasma alemão ou escandinavo ou hindustânico do Quixote," é impossível negar que o valor de uma obra está menos associado às suas minúcias particulares originais do que à sua significância cultural e universal. Tal significância pode ser alcançada somente quando o autor compreende que não é de fato o autor de suas obras, ou, pelo menos, não é o único autor. Toda obra implica uma herança genética de influências e convergências, de imitações e homenagens, de alusões e memórias.

\footnotetext{
${ }^{19}$ Jorge Luis Borges, Discussão, 1932, in Obras Completas Vol. I, p. 256.

${ }^{20}$ Ibid.

${ }^{21}$ Jorge Luis Borges, Discussão, 1932, in Obras Completas Vol. I, p. 260.

22 Jorge Luis Borges, Otras inquisiciones, 1952, p. 163.
} 
Esse fluxo de confluências e vozes lembra o rio de Heráclito, o filósofo pré-socrático que afirmou ser impossível entrar duas vezes no mesmo rio, uma vez que já não será o mesmo rio. Da mesma maneira, é impossível ler ou escrever duas vezes o mesmo livro, posto que o fluxo textual das consciências do autor e do leitor estão sempre mudando. Logo, podemos concluir que não existe um livro único, original, puro, imutável; existem apenas variações, traduções, edições, improvisações, leituras parciais. Todas as obras são abandonadas, e será somente quando o leitor encontrar a obra que essa poderá ser completada.

Richard Costa

rich.hard.costa@gmail.com

Graduando, Universidade Federal de Santa Catarina

\section{Referências biliográficas}

Borges, Jorge Luis. Obras Completas Vol. I. Vários tradutores. São Paulo, Globo, 2000.

. Otras inquisiciones. Buenos Aires, Emecé, 1986. 